\title{
Rates of production of volatile fatty acids in the rumen of grazing sheep and their relation to ruminal concentrations
}

\author{
By R. A. LENG \\ Department of Biochemistry and Nutrition, \\ University of New England, Armidale, NSW 235 I, Australia \\ AND J. L. CORBETT AND D. J. BRETT \\ CSIRO, Pastoral Research Laboratory, Armidale, NSW 235I, Australia \\ (Received 22 March 1967-Accepted 18 $\not 3 u l y$ 1967)
}

\begin{abstract}
1. The rates of production, or entry rates, of acetic, propionic and butyric acids in the rumen of grazing sheep have been measured by a radioisotope technique previously used on penned animals.

2. Regression equations were derived relating entry rates to ruminal concentrations. The equations from penned and grazing sheep did not differ significantly.

3. The standard errors of entry rates predicted for a single sheep from equations based on all results were calculated to be $\pm 0.60,0.18$ and $0.15 \mathrm{~m}-\mathrm{mole} / \mathrm{min}$ for acetic, propionic and butyric acids respectively.

4. Interconversions between acetic and butyric acids in the rumen were similar in extent to those found in penned sheep. These values were used to calculate from entry rates the net amounts of the acids becoming available to the animals.

5. An equation was derived that permits the amount of energy supplied to an animal by the acids to be predicted from concentrations with a standard error of $\pm 0.17 \mathrm{kcal} / \mathrm{min}$.

6. The applicability of the prediction equations is discussed.
\end{abstract}

Isotope dilution techniques have been used widely on housed animals to measure the entry rates of a variety of metabolites into body pools, and necessarily they have been developed in well-controlled laboratory conditions. If such studies are to lead to improved animal production they should be extended to include animals under other forms of management and subject to a wide range of nutritional and environmental conditions. In particular, studies should be made on animals at pasture, which is the principal source of feed for the world's cattle and sheep.

Procedures for measuring the rates of production in the rumen, or entry rates into the rumen pools, of the volatile fatty acids (VFA), acetic, propionic and butyric, either singly or simultaneously, have been described (Leng \& Leonard, r965; Leng \& Brett, I966). These procedures have now been used to measure the rates of production of VFA in grazing sheep. A brief report on the work has been made elsewhere (Leng, Brett \& Corbett, 1966).

\section{EXPERIMENTAL}

\section{Animals and pastures}

Entry rates were measured in nine adult Merino ewes which had not been used in the earlier work. Their live weights varied from 35 to $45 \mathrm{~kg}$, including fleeces of about $3 \mathrm{~kg}$. Each animal was fitted with a permanent rumen cannula. The four pastures of 
Phalaris tuberosa used, $0.5^{-2}$ acres in area, provided herbage that varied in stage of maturity from short and leafy to mature and stemmy. Other plant species present included Hordeum leporinum and Trifolium repens but they made only small contributions to the herbage available. The sheep grazed the pastures in flocks of from four to nine animals and no experiment was made until the sheep used had been on one pasture for at least 3 weeks.

Feed intakes were estimated to gain information on the nature of the animals' diets. Grazing behaviour was observed to determine the degree of regularity in eating.

Feed intakes. Feed intakes were estimated over 5- or 10-day periods that included the days when an infusion was made. Each animal in a flock, including the infused sheep, was dosed with $\mathrm{I} g$ chromium sesquioxide $\left(\mathrm{Cr}_{2} \mathrm{O}_{3}\right)$ in a gelatin capsule twice daily and at each time a sample of faeces was taken manually from the rectum. For each sheep the samples were combined over the 5- or 10-days for analysis. The accuracy of this procedure for determining the mean $\mathrm{Cr}_{2} \mathrm{O}_{3}$ concentration, and hence faecal output, was checked by harnessing some animals for the total collection of faeces and analysing a representative sample as described by Langlands, Corbett, McDonald \& Reid (1963). No serious bias was found.

Samples of grazed herbage were obtained from one or two sheep with permanent oesophageal fistulas which were added to each flock of experimental animals; the fistulas were as described by McManus, Arnold \& Hamilton (I962). The digestibility in vitro of each sample, dried at $60^{\circ}$ and ground, and of a range of samples of known digestibility in vivo, was determined by a method similar to that described by Alexander \& McGowan (I96I). The estimates of digestibility in vivo that could then be obtained were generally in good agreement with the values predicted from the percentage of nitrogen in the faeces of the experimental animals by means of the equation of Lambourne \& Reardon (I963).

Table I. Digestibility of pasture herbage grazed by groups of sheep that included the animal(s) used for measurements of VFA entry rates, and estimated mean daily intakes of digestible organic matter $(D O M)$

\begin{tabular}{|c|c|c|c|}
\hline Pasture & Sheep no. & $\begin{array}{c}\text { Organic } \\
\text { matter } \\
\text { digestibility } \\
(\%)\end{array}$ & $\begin{array}{l}\text { Mean intake } \\
\text { of DOM } \\
\text { (g/head } \\
\text { day) }\end{array}$ \\
\hline A & 2 & 58 & $26_{5}$ \\
\hline B & 4 & 66 & $3 \times 5$ \\
\hline $\begin{array}{l}\text { B } \\
\text { B }\end{array}$ & $\left.\begin{array}{l}5 \\
6\end{array}\right\}$ & 64 & 350 \\
\hline C & 7 & 72 & 490 \\
\hline $\begin{array}{l}\mathbf{D} \\
\mathrm{D}\end{array}$ & $\left.\begin{array}{l}8 \\
9\end{array}\right\}$ & 63 & 310 \\
\hline $\begin{array}{l}\text { A } \\
\text { A }\end{array}$ & $\left.\begin{array}{l}\text { IO } \\
\text { II }\end{array}\right\}$ & 56 & 400 \\
\hline
\end{tabular}

The values for faecal output and herbage digestibility were combined to give estimates of intake. The results obtained are summarized in Table I. Because of the variability in intake between sheep and between days, the values for mean intakes 
should not be taken to represent the intake of a particular sheep on a particular day when VFA measurements were made.

Grazing behaviour. The times and duration of periods of grazing by, on average, four sheep in a flock were observed by the method of Allden (1962) in fifteen periods of $24 \mathrm{~h}$ distributed among the experiments. Generally, grazing commenced each day between 05.00 and $06.00 \mathrm{~h}$, and by $08.00 \mathrm{~h}$ about $75 \mathrm{~min}$ had been spent in this activity. In each of the following two $2 \mathrm{~h}$ periods the animals grazed for about $\mathrm{I}$ h. The mean total grazing time was about $9.5 \mathrm{~h}$ per day.

\section{Infusion of labelled acids}

Equipment. A small battery-powered solenoid pump (Lambda Pump; Harvard Apparatus Co., Mass., USA) was mounted on a belt secured around the sheep. It delivered $0.0 \mathrm{Iml} / \mathrm{stroke}$ at intervals of time which could be varied by altering the setting of an activator. A reservoir of infusate was contained in a polythene bag of about $150 \mathrm{ml}$ capacity, such as is used in blood transfusions, and this was also attached to the belt. The whole equipment with protective cover weighed about $\mathrm{I} \mathrm{kg}$ and is shown in P1. r. As in previous experiments with penned sheep (Leng \& Leonard, 1965) a curved polythene tube was attached to the inside of the rumen cannula. The catheter tube from the pump, passing through this tube, delivered the infusate into the anterior region of the rumen.

Procedure. The activator was set so that the pump delivered $0.0 \mathrm{Iml}$ of infusate at intervals of approximately $2 \mathrm{sec}$, that is $0.3 \mathrm{ml} / \mathrm{min}$. The exact rate of delivery was determined from bench tests made over periods of several hours; a further check was made in the field by measuring the loss in weight of the reservoir during each of the infusions, which were of known duration.

Measurements of the entry rates of metabolites by the continuous infusion technique must be made under steady-state conditions. In particular, the constant-rate infusion has to be made during a period when VFA concentrations in the rumen are approximately constant and specific radioactivity has to reach a steady level as evidence that VFA pool size is not changing. The period chosen for the infusions was the $6 \mathrm{~h}$ from 08.00 to $\mathrm{I} 4.00 \mathrm{~h}$ since it was expected from the observations of grazing behaviour, and later confirmed, that only small changes in VFA concentrations would be encountered. At $07.30 \mathrm{~h}$ on the day of an experiment the sheep were brought into a yard and the belt and equipment were fitted to one of them; all animals had been accustomed to the procedure. The flock was returned to the pasture by $08.00 \mathrm{~h}$. At hourly intervals from 10.00 or $11.00 \mathrm{~h}$ to $14.00 \mathrm{~h}$ the test animal was brought back into the yard with as little disturbance as possible and a total of about $20 \mathrm{ml}$ of fluid was withdrawn by suction from several sites in the rumen and acidified with $0.2 \mathrm{ml}$ of $10 \mathrm{~N}-$ $\mathrm{H}_{2} \mathrm{SO}_{4}$. This procedure took no more than $10 \mathrm{~min}$, and between samplings the test animals always appeared to graze normally and to behave in a manner similar to their companions.

Infusate. Solutions for infusion were prepared and tested as previously described (Leng \& Brett, 1966 ) from the sodium salts of $\left[\mathrm{U}-{ }^{14} \mathrm{C}\right]$ acetate, $\left[{ }^{1}-{ }^{14} \mathrm{C}\right]$ propionate, $\left[\mathrm{I}^{-14} \mathrm{C}\right]$ butyrate, $\left[2-{ }^{14} \mathrm{C}\right]$ butyrate, $\left[2-3^{-}-T\right]$ butyrate (all from the Radiochemical Centre, 
Amersham) and $\left[2-^{14} \mathrm{C}\right]$ - and $\left[3^{-14} \mathrm{C}\right]$-propionate (from Phillips-Duphar, N.V., Amsterdam). In the present experiments the reservoir of infusate was close to the body of the sheep and so warmed. To determine if there was any breakdown of the acids in these conditions detailed analyses and assays of specific radioactivity were made of the solution remaining in the reservoir at the end of each experiment. In all instances all label was accounted for in the acids.

Six sheep received infusions of a solution containing approximately $0.45 \mu \mathrm{c}$ [U-14 $\mathrm{C}$ ]acetate, $0.36 \mu \mathrm{c}\left[\mathrm{U}-{ }^{14} \mathrm{C}\right]$ propionate and $\mathrm{I} \cdot 45 \mu \mathrm{c}[2-3-T]$ butyrate per $\mathrm{ml}$. The remaining three sheep, nos. 6,9 and $\mathrm{II}$, received a solution containing approximately $0.3 \mu \mathrm{c}\left[\mathrm{I}-2-{ }^{14} \mathrm{C}\right]$ butyrate and $\mathrm{I} \cdot 5 \mu \mathrm{c}[2-3-T]$ butyrate per $\mathrm{ml}$.

\section{Chemical methods}

The methods used for the determination and isolation of individual VFA in infusate and in ruminal fluid, and for the measurement of their radioactivity, have been described previously (Leng \& Leonard, 1965; Leng \& Brett, 1966).

\section{RESULTS}

Results of a typical experiment on the specific radioactivities $\left(S_{A}, \mu \mathrm{c} / \mathrm{mole}\right)$ and concentrations of the acids in the rumen are given in Table 2. They show that the requirement of essentially steady-state conditions was satisfied about $3 \mathrm{~h}$ after infusion at a constant known rate $\left(S_{l}, \mu \mathrm{c} / \mathrm{min}\right)$ was started. Measurements of entry rates $\left(S_{t} / S_{A}\right)$, expressed as $\mathrm{m}$-moles/min, could then be made.

The proportion of the acetic acid produced in the rumen that arose by conversion of butyric acid was determined by comparing the ${ }^{14} \mathrm{C}$ specific radioactivities $(\mu \mathrm{c} / \mathrm{g} \mathrm{C})$ of acetic and butyric acids isolated from the rumen in the three experiments where $\left[\mathrm{I}-2-{ }^{14} \mathrm{C}\right]$ - and $[2-3-T]$ butyrates were infused. There was negligible transfer $(<\mathrm{I} \%)$ of carbon from the $\left[{ }^{1}-2-{ }^{14} \mathrm{C}\right]$ butyrate to propionic acid, a finding in agreement with the earlier work and that of Bergman, Reid, Murray, Brockway \& Whitelaw ( $\mathrm{I}^{6} 65$ ) where, in both instances, it was found that interconversions between propionic and butyric acids, as between propionic and acetic, were small in extent. In addition, in all three experiments, as in those of Leng \& Brett (1966), the tritium to ${ }^{14} \mathrm{C}$ ratios in samples of butyric acid isolated from the rumen were the same as the ratios in the infusates. Thus it was again confirmed that the entry rate of butyric acid could be measured by infusing butyrate labelled with tritium only, as was done in the six experiments in which acetic and propionic acids were also measured. The percentage of butyric acid arising from acetic acid was determined by comparing the ${ }^{14} \mathrm{C}$ specific radioactivities of the acids isolated during five of these experiments.

The mean values in each experiment for the concentrations and molar proportions of VFA in the rumen, their entry rates, and their interconversions (Table 3) were obtained from the analyses of the four samples taken during the period II.00-I $4.00 \mathrm{~h}$.

Examination of these values showed that the concentrations in the rumen (m-moles/1.) of acetic $\left(X_{\mathrm{ac}}\right)$, propionic $\left(X_{\mathrm{pr}}\right)$ and butyric $\left(X_{\mathrm{bu}}\right)$ acids were linearly related to the 
Vol. 22

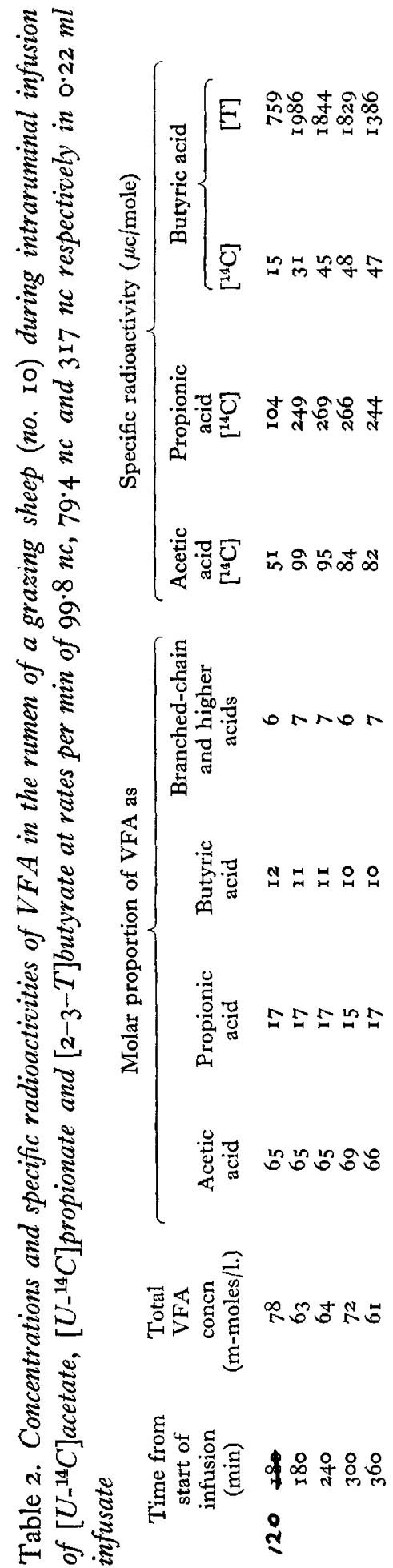




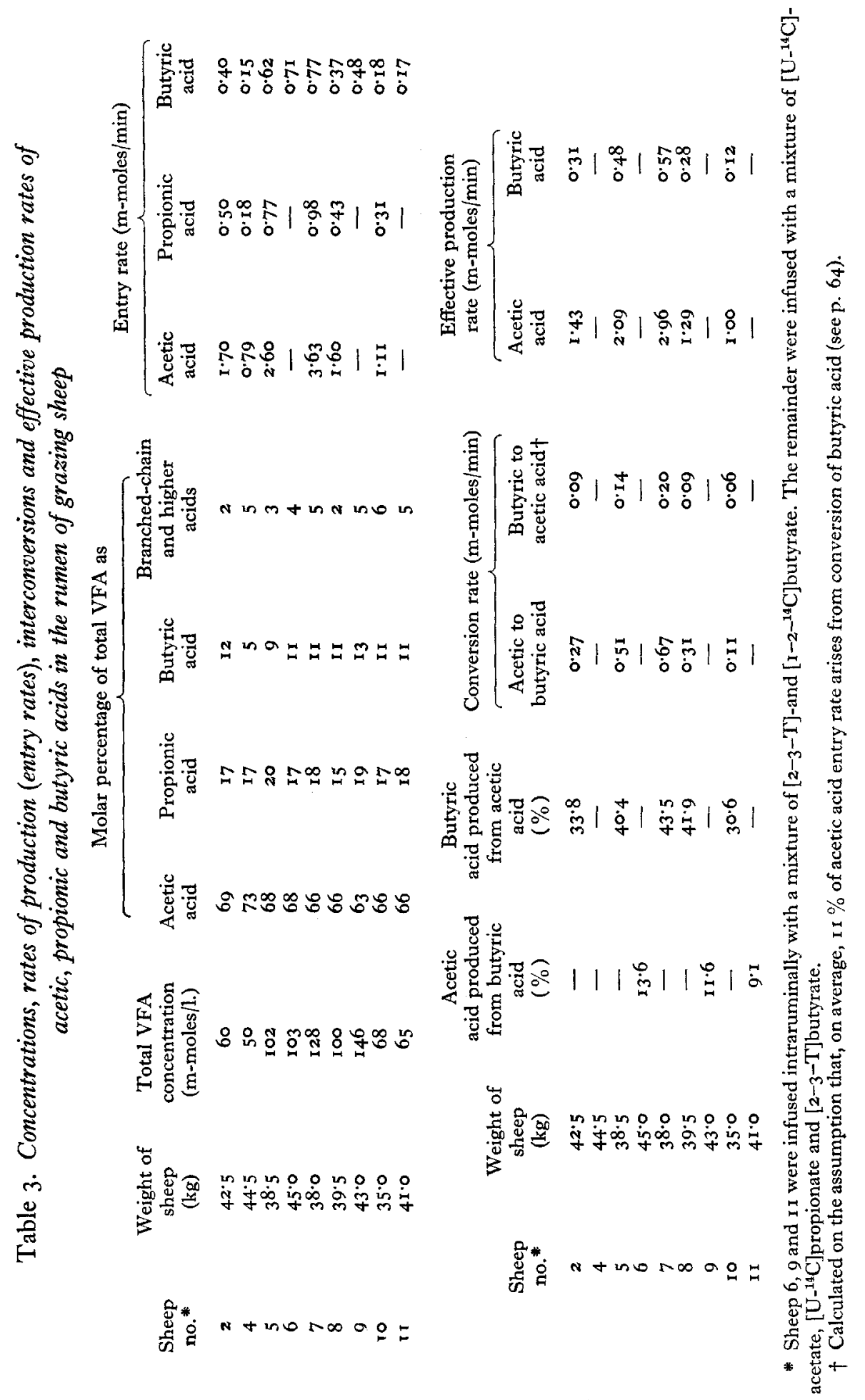


corresponding entry rates $\left(Y_{\mathrm{ac}}, Y_{\mathrm{pr}}, Y_{\mathrm{bu}}, \mathrm{m}\right.$-moles/min). The regression equations derived, the standard errors of the regression coefficients (SE), and the residual standard deviations (RSD), based on six, six and nine experiments respectively, were:

$$
\begin{array}{lll}
Y_{\mathrm{ac}}=0.049 X_{\mathrm{ac}}-0.887, & \mathrm{SE} \pm 0.012, & \mathrm{RSD} \pm 0.528, \\
Y_{\mathrm{pr}}=0.045 X_{\mathrm{pp}}-0.147, & \mathrm{SE} \pm 0.010, & \mathrm{RSD} \pm 0.133, \\
Y_{\mathrm{bu}}=0.020 X_{\mathrm{bu}}+0.14 \mathrm{I}, & \mathrm{SE} \pm 0.015, & \mathrm{RSD} \pm 0.203 .
\end{array}
$$

The regression coefficient in equation (3) was not significant, but this relationship and the other two are very similar to those derived from the studies with penned sheep (Leng \& Brett, I966) as is shown in Fig. I. It was confirmed that there were no

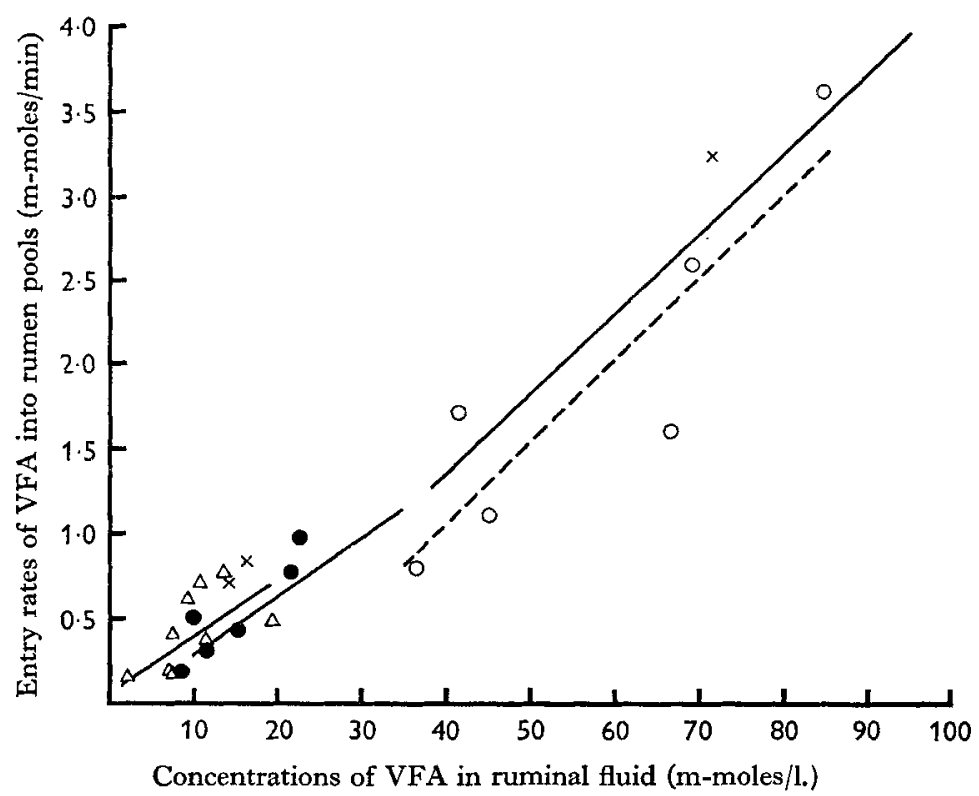

Fig. I. Concentrations of volatile fatty acids in ruminal fluid and their entry rates into rumen pools in grazing sheep. $\Delta$, butyric acid;, propionic acid; 0 , acetic acid; $x$, values of Bergman et al. $(1965)$ for, from left to right, butyric, propionic and acetic acids. Solid lines are the relationships between concentrations and entry rates obtained by Leng \& Brett (r 966 ) for penned sheep for, from left to right, butyric, propionic and acetic acids. The broken line is the relationship for acetic acid obtained for the grazing sheep. Lines for the other two acids could not be clearly distinguished from those for the penned animals and have not been plotted.

significant differences between the relationships from pen and pasture and the equations derived when the two sets of results were combined were:

$$
\begin{array}{lll}
Y_{\mathrm{ac}}=0.048 X_{\mathrm{ac}}-0.648, & \mathrm{SE} \pm 0.006, & \mathrm{RSD} \pm 0.560, \\
Y_{\mathrm{pr}}=0.037 X_{\mathrm{pr}}-0.078, & \mathrm{SE} \pm 0.005, & \mathrm{RSD} \pm 0.162, \\
Y_{\mathrm{bu}}=0.032 X_{\mathrm{bu}}+0.085, & \mathrm{SE} \pm 0.006, & \mathrm{RSD} \pm 0.143 .
\end{array}
$$

These equations are based on twenty-one, twenty-one and twenty-four experiments respectively.

There was also similarity between the two studies in the values obtained for inter- 
conversions between acetic and butyric acids and it did not appear that their magnitude was related to the relative concentrations of the acids in the rumen. When all results were combined the proportion of the butyric acid produced that arose from acetic acid, as a mean with standard error based on a total of ten observations, was $4 \mathrm{I} \cdot 3 \pm \mathrm{I} \cdot 6 \%$. It was found from a total of seven observations that, of the acetic acid produced, I $\mathbf{I} \cdot \pm \pm \mathrm{I} \cdot 0 \%$ arose from butyric acid. These values are indices of the extent to which the measurements of entry into the rumen pools overestimated effective production rates (Leng \& Leonard, 1965), that is the net amounts of the acids that may actually become available to the animals.

As shown in Table 3 , effective production rates for acetic and butyric acids were calculated by subtracting from the measured entry rate for the one acid the amount that was converted into the other; it was assumed that 2 moles of acetate yield I mole of butyrate and vice versa. Effective production rates for the two acids in each of twenty-one sheep were calculated in this manner by applying the average conversions, I I. $\% \%$ of acetate from butyrate and $4 \times 3 \%$ of butyrate from acetate, to the individual measured entry rates. For acetic acid the mean of the values obtained, with standard error, was $86.4 \pm \mathrm{r} \cdot 0 \%$ of entry rate and for butyric acid it was $6 \mathrm{r} \cdot 8 \pm 3.4 \%$. The effective production rate of propionic acid was taken to be the same as the measured rate because, as already stated, the acid has not been found to be involved in other than small-scale interconversions.

If an entry rate for acetic acid $\left(Y_{\mathrm{ac}}\right)$ is calculated from a determined ruminal concentration by the use of equation (4), the effective production rate may be estimated as $\left(Y_{\mathrm{ac}} \times 0.864\right) \mathrm{m}$-moles $/ \mathrm{min}$ or $\left(Y_{\mathrm{ac}} \times 0.864 \times 0.209\right) \mathrm{kcal} / \mathrm{min}$. The appropriate factors to make similar use of equations $(5)$ and $(6)$ would be $(1 \cdot 0,0.367)$ and $(0.618$, $0.524)$ respectively. Such estimates for individual acids will often be of less interest than the total amounts of energy supplied to animals by all three VFA, and these amounts could be calculated for a total of seventeen sheep, including the six in the present work, in which measurements of simultaneous entry rate had been made. The results were then examined to determine if the total energy values $\left(Y_{k}, \mathrm{kcal} / \mathrm{min}\right)$ were related to the acid concentration most easily measured, namely that of total steamvolatile acids $\left(X_{l}, \mathrm{~m}\right.$-moles/1.). In a series of regression analyses it was established (I) that there was a significant relationship between these two variables; (2) that the results for pen and pasture were homogeneous; (3) that an equation including quadratic or higher terms did not give a significantly better fit to the results than did a rectilinear equation; and (4) that the equation derived when $Y_{k}$ was calculated by using the values appropriate to the particular sheep or diet for the fractions of the measured entry rates that were effective was virtually indistinguishable from equation (7) given below, where the mean values, 0.864 and 0.618 , had been used.

$$
Y_{k}=0.0105 X_{t}-0.27 \mathrm{I} 6, \quad \mathrm{SE} \pm 0.001 \mathrm{I}, \quad \mathrm{RSD} \pm 0.164 \mathrm{I} .
$$




\section{DISCUSSION}

Since VFA concentrations in the rumen were found to reflect their entry rates in penned sheep given a variety of diets it could perhaps be supposed that they would also do so in grazing sheep; it could be regarded as likely that the complex set of events within the rumen that interact to yield such relationships would be fundamentally similar in both circumstances. The necessary confirmation by experiment has now been obtained and the close agreement between the two sets of results is striking.

The merit of the equations lies principally in the use that might be made of them for predictive purposes. Production rates, though expressed as $\mathrm{m}$-moles VFA/min, were measured over periods of several hours, the steady-state periods when the infusions were made, but they could not be measured continuously for $24 \mathrm{~h}$ at pasture because there was no way by which VFA concentrations within the rumen of freely grazing sheep could be held constant for this length of time. With the penned sheep, the hourly feeding that promoted uniform conditions in the rumen could not be extended over longer periods than $\mathrm{I} 2 \mathrm{~h}$ for technical reasons. Even if concentrations could have been held constant for $24 \mathrm{~h}$ or more, the infusion periods themselves could not, with confidence, have been greatly extended because of the possibility that ${ }^{14} \mathrm{C}$ would be re-cycled and fixed in the rumen, leading to spurious values for the specific radioactivities of the acids and for their entry rates. Observations by Leng \& Leonard ( 1965 ) on $\mathrm{CO}_{2}$ fixation in the rumen indicated that re-cycling would be unimportant in the $6 \mathrm{~h}$ infusions made in these experiments. The infusions at pasture were all made during the first part of the day because it could be expected that VFA concentrations would be steady at this time and, for a similar reason, measurements in the penned sheep were made in the afternoon or evening.

It is probable, however, that the equations can be used to obtain valid estimates of the quantities of VFA produced in $24 \mathrm{~h}$. If an acid entry rate is represented by a particular concentration during some parts of the day there is no obvious reason why that concentration should not also represent a similar entry rate at other times. It also seems reasonable to suppose that if acid concentrations in the rumen of a sheep were determined at regular intervals over $24 \mathrm{~h}$, integration of the estimates of entry rates that could then be obtained would yield meaningful information on the total amounts of acids produced during that period.

In practice, the integration of estimates of entry rates made for short periods of time would be achieved most simply by analysing a sample of digesta that resulted from continuous automatic collection or comprised a number of subsamples taken at regular intervals. Measurements of this type have been made by Gray, Weller, Pilgrim \& Jones (1966, 1967) and Weller, Gray, Pilgrim \& Jones (1967) but most of their results were not obtained under steady-state conditions. Gray et al. (1966) attempted to match the rate of infusion of labelled acid with the varying acid concentration in the rumen of sheep fed once each $12 \mathrm{~h}$ so that ${ }^{14} \mathrm{C}$ specific radioactivities were held approximately constant. They also infused at a constant rate, as did Weller et al. (1967), and determined $12 \mathrm{~h}$ mean specific radioactivities. Entry rates in these two experiments 
were calculated by reference to the rate and the amount of the infusion respectively. These approaches are valid only if the implicit assumption that the concentration of an acid reflects its entry rate is correct. We have shown this to be so, and there is confirmatory evidence in the most recent work of Gray et al. (1967) in which a number of feeding regimes that would have promoted different patterns of ruminal VFA concentration yielded similar results for the $12 \mathrm{~h}$ production of VFA from a standard ration, whether the measurements were made during the daytime or at night.

The view that our equations can be used to predict for $24 \mathrm{~h}$ periods appears to be tenable when the findings of Gray and his colleagues and our work are considered together. If $24 \mathrm{~h}$ mean concentrations of acetic, propionic, butyric, and total VFA, in the rumen were $64.8,18.9,9.8$ and $101 \cdot 3 \mathrm{~m}$-moles/l. respectively, which were the mean values for respectively twenty-one, twenty-one, twenty-four and seventeen sheep used in our experiments, then equations (4), (5), (6) and (7) would indicate effective production rates of approximately $3 \cdot 1,0.9$ and 0.4 moles/day and $1140 \mathrm{kcal} /$ day. This amount of energy, akin to metabolizable energy, would ordinarily be sufficient to maintain a sheep of some $40 \mathrm{~kg}$ live weight. In an earlier paper (Leng \& Leonard, 1965), some estimates were made of daily effective production rates on the working assumption that production and concentration varied pari passu. If the $24 \mathrm{~h}$ mean concentrations used in those calculations are now substituted in equations (4), (5) and (6) above, the values for entry rates obtained are $2.30,0.47$ and $0.30 \mathrm{~m}$-moles $/ \mathrm{min}$ respectively, or $3.3 \mathrm{I}, 0.68$ and $0.43 \mathrm{moles} / 24 \mathrm{~h}$. These values represent an effective energy contribution of $988 \mathrm{kcal} /$ day which is $52.6 \%$ of the digestible energy of the ration then used. A value about $8 \%$ lower is obtained by an alternative method of calculation: the total VFA concentration including higher acids was $86.3 \mathrm{~m}$-moles $/ 1$. and substitution in equation (7) gives an estimate of $0.635 \mathrm{kcal} / \mathrm{min}$ or $914 \mathrm{kcal} / \mathrm{day}$.

All the above estimates appear to be reasonable and, in view of the wide range of conditions in which they were obtained, they can be taken to indicate that considerable confidence may be placed in the techniques of measurement used. The estimates are of the same order of magnitude as those reported by Gray and his colleagues, some of which (Gray et al. 1967) were obtained using sheep given a constant amount of feed each hour. The total air-dry weight of chaffed wheaten and lucerne hays given in $12 \mathrm{~h}$ by Gray et al. (1967) was $0.5 \mathrm{~kg} ; 2.06$ moles of VFA were produced, representing $52 \%$ of the digestible energy of the feed. There are also similarities between our results and those obtained by Bergman et al. (I965) from sheep fed on dried grass cubes every few minutes at the rate of $900 \mathrm{~g} /$ day; the concordance is illustrated in Fig. I where the mean values for entry rates and concentrations are plotted.

The residual standard deviations for equations (4), (5), (6) and (7) were respectively $22 \cdot 6,26 \cdot 2,35.4$ and $20.5 \%$ of the corresponding mean entry rates, and it was calculated that over the ranges encountered the standard errors of predicted observations would be approximately $\pm 0.60,0.18,0.15 \mathrm{~m}-\mathrm{mole} / \mathrm{min}$ and $0.17 \mathrm{kcal} / \mathrm{min}$ respectively. It is surprising that it has been possible to combine values for many animals given a wide range of diets and describe so complex a biological system in such simple terms. It does not appear that precision would be much altered if relationships were derived for restricted ranges of feeds because of the similarity between the results from 
a variety of dry feeds and those from fresh pasture herbage. It is a possibility that the relationships may be widely applicable among feeds because characteristics that affect the rates of production of VFA in the rumen may also promote corresponding changes in acid concentrations. Thus a decrease in the rate of digestion of a feed, manifested as a reduction in production rate, might promote an increase in rumen volume and, a priori, a reduction in VFA concentration. This view receives some support from the fact that significant regression relationships were derived from results that included the measurements made on sheep in which ruminal fluid volumes were found (Leng \& Brett, I966) to vary between $2 \cdot 9$ and $6 \cdot 21$.

The possibility was considered that other measurements made on the animals or on feeds might be used to increase the precision of the relationships and so give further indications of how widely applicable they might be. The rates of absorption and passage of VFA from the rumen could not be estimated but they would, in any event, probably be fairly closely correlated with concentrations. Concentrations would also be affected by conversions into other substances within the rumen, but there is little detailed information on factors determining their direction and extent. The report by Whanger $\&$ Matrone ( 1965 ) that the synthesis of butyric and higher fatty acids from acetate is dependent on an adequate supply of sulphur suggests that the equations obtained might be less appropriate for sheep eating feeds deficient in this nutrient.

Although, because of the deliberate use of a large number of sheep, acid levels and entry rates were confounded with differences between animals it was considered that the information gained would be more generally useful, if somewhat less precise, than that from measurements made on a few sheep only. Multiple regression analyses were made with live weight (corrected to standard fleece weight) and with rumen $\mathrm{pH}$ in addition to VFA concentration as independent variables, but their inclusion did not in either instance effect a significant reduction in residual variability. The range in live weight of the sheep, which included some used earlier, was from 26 to $42 \mathrm{~kg}$, and it is noteworthy that the apparently compatible results of Bergman et al. (1965) were obtained from sheep weighing $10-13 \mathrm{~kg}$ more than the heaviest animals used by us.

It can be concluded that equations (4) to (7) inclusive could be used to obtain useful information on roughage, concentrate and roughage, or pasture diets consumed by adult sheep varying quite widely in size. For example, if two pastures were each grazed by ten sheep of similar type and the total VFA concentration in every animal was determined on one occasion, there would be an $80 \%$ chance that a mean difference of about $0.2 \mathrm{kcal} / \mathrm{min}$ in the energy of VFA predicted from equation (7) would be found significant at $P<0.05$. This difference would be represented by a difference in VFA concentration of about $20 \mathrm{~m}$-moles/1. It seems reasonable to suppose, though subject to proof, that the energy supplied by VFA in $24 \mathrm{~h}$ to a single animal could be predicted from the $24 \mathrm{~h}$ mean concentration with a standard error of $\pm 245 \mathrm{kcal}$. Further work is in progress to examine the contributions of differences between times of day, between diets and between sheep, including lambs, to the variability in the concentration:production relationships and to assess their use for $24 \mathrm{~h}$ predictions. 
We are indebted to the Australian Wool Board and the Rural Credits Development Fund for financial support for this work. We thank J. Wilcher, G. S. McArthur and G. H. Parkinson for their skilled technical assistance.

\section{REFERENCES}

Alexander, R. H. \& McGowan, M. (I961). F. Br. Grassl. Soc. 16, 275.

Allden, W. G. (1962). Proc. Aust. Soc. Anim. Prod. 4, I63.

Bergman, E. N., Reid, R. S., Murray, M. G., Brockway, J. M. \& Whitelaw, F. G. (1965). Biochem. F.

97, 53 .

Gray, F. V., Weller, R. A., Pilgrim, A. F. \& Jones, G. B. (1966). Aust. F. agric. Res. 17, 69.

Gray, F. V., Weller, R. A., Pilgrim, A. F. \& Jones, G. B. (r967). Aust. F. agric. Res. r8, 625.

Lambourne, L. J. \& Reardon, T. F. (1963). Aust. F. agric. Res. 14, 257.

Langlands, J. P., Corbett, J. L., McDonald, I. \& Reid, G. W. (1963). Br. F. Nutr. 17, 2 I I.

Leng, R. A. \& Brett, D. J. (1966). Br. F. Nutr. 20, 541.

Leng, R. A., Brett, D. J. \& Corbett, J. L. (I966). Proc. int. Congr. Nutr. vrir. Hamburg (In the Press.) Leng, R. A. \& Leonard, G. J. (1965). Br. F. Nutr. 19, 469.

McManus, W. R., Arnold, G. W. \& Hamilton, F. J. (r962). Aust. vet. F. 38, 275.

Weller, R. A., Gray, F. V., Pilgrim, A. F. \& Jones, G. B. (1967). Aust. F. agric. Res. 18, 107.

Whanger, P. D. \& Matrone, G. (1965). Biochim. biophys. Acta 98, 454.

\section{EXPLANATION OF PLATE}

(a) Infusion apparatus. The infusion pump (bottom left) is activated at regular intervals by a battery and timer (right). At each stroke the pump delivers $0.01 \mathrm{ml}$ infusate, drawn from the adjacent plastic reservoir of $150 \mathrm{ml}$ capacity. The catheter attached to the pump passes through the curved plastic tube $(A)$, which penetrates the Perspex plug closing the rumen cannula, so that the infusate is delivered into the anterior region of the rumen. The pump is photographed on top of the carrying belt which is secured around the sheep.

(b) Infusion apparatus attached to a sheep showing infusate being delivered into the rumen. Samples are withdrawn from the rumen through a port in the Perspex plug. The apparatus is protected by a padded cover which, in the photograph, is partly detached and dropped behind the foreleg. 
British Fournal of Nutrition, Vol. 22, No. I

Plate I

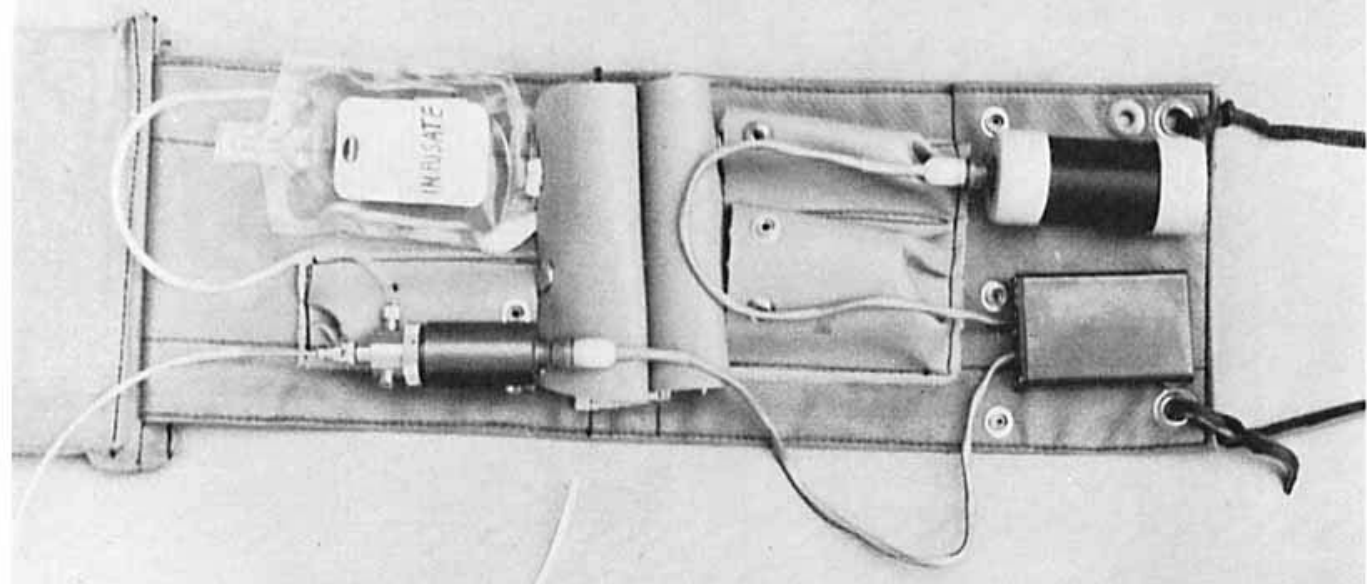

A

$a$

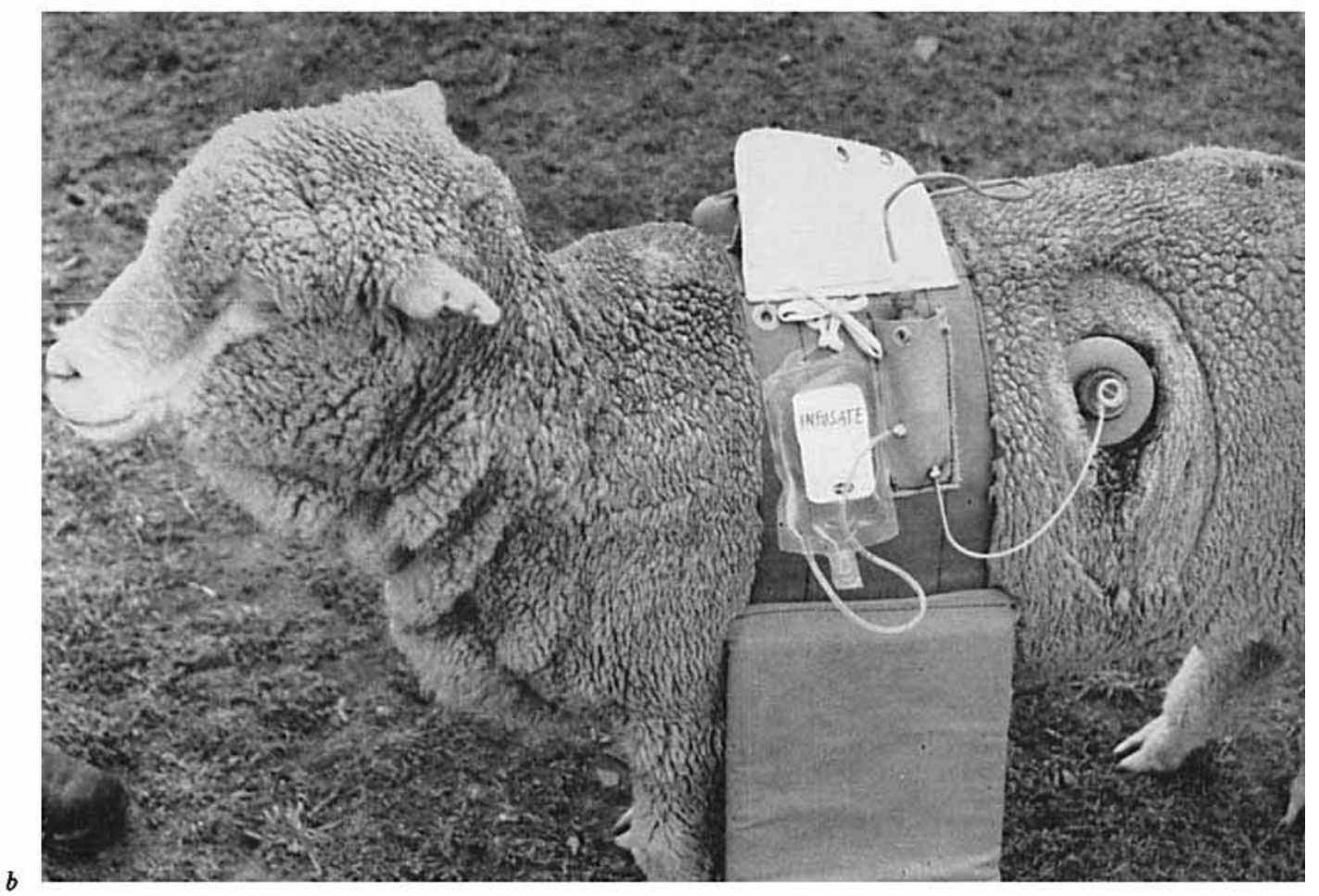

R. A. LENG, J. L. CORBETT AND D. J. BRETT

(Facing p, 68) 